\title{
Sustentabilidade de sistemas socioambientais: comparativo entre a Região Hidrográfica VIII do estado do Rio de Janeiro e sua zona costeira
}

Durabilité des systèmes socio-environnementaux: comparaison entre la région hydrographique VIII de l'État de Rio de Janeiro et sa zone côtière Sustainability of socio-environmental systems: comparative between the VIII ${ }^{\text {th }}$ hydrographic region of Rio de Janeiro state and its coastal zone Sostenibilidad de sistemas socioambientales: comparativo entre la Región Hidrográfica VIII del estado del Rio de Janeiro y su zona costera

Antonio Vinicius Lamblet Mafort, Ana Carolina da Conceição Rodrigues, Maria Inês Paes Ferreira e Romeu e Silva Neto

\section{(2) OpenEdition}

\section{Journals}

Edição electrónica

URL: http://journals.openedition.org/espacoeconomia/8335

DOI: $10.4000 /$ espacoeconomia.8335

ISSN: 2317-7837

Editora

Núcleo de Pesquisa Espaço \& Economia

Refêrencia eletrónica

Antonio Vinicius Lamblet Mafort, Ana Carolina da Conceição Rodrigues, Maria Inês Paes Ferreira e Romeu e Silva Neto, «Sustentabilidade de sistemas socioambientais: comparativo entre a Região Hidrográfica VIII do estado do Rio de Janeiro e sua zona costeira », Espaço e Economia [Online], 15 | 2019, posto online no dia 02 novembro 2019, consultado o 14 novembro 2019. URL : http:// journals.openedition.org/espacoeconomia/8335; DOI : 10.4000/espacoeconomia.8335

Este documento foi criado de forma automática no dia 14 novembro 2019

(C) NUPEE 
Sustentabilidade de sistemas socioambientais: comparativo entre a Região Hidrográfica VIII do estado do Rio de Janeiro e sua zona costeira

Durabilité des systèmes socio-environnementaux: comparaison entre la région hydrographique VIII de l'État de Rio de Janeiro et sa zone côtière Sustainability of socio-environmental systems: comparative between the VIII ${ }^{\text {th }}$ hydrographic region of Rio de Janeiro state and its coastal zone Sostenibilidad de sistemas socioambientales: comparativo entre la Región Hidrográfica VIII del estado del Rio de Janeiro y su zona costera

Antonio Vinicius Lamblet Mafort, Ana Carolina da Conceição Rodrigues, Maria Inês Paes Ferreira e Romeu e Silva Neto

\section{Introdução}

1 A assembleia geral das Nações Unidas (ONU) aprovou em setembro de 2015, por meio de consenso entre os países membros da Organização, um acordo histórico: a Agenda 2030 para o Desenvolvimento Sustentável, a qual inclui os Objetivos de Desenvolvimento Sustentável (ODS), um instrumento global com alcance e importância sem precedentes: melhorar notavelmente a vida de todas as pessoas e transformar o mundo em um lugar melhor (ONUBR, 2018).

Os dezessete ODS acordados na Agenda 2030 (ONU, 2015) abordam algumas das barreiras sistêmicas ao desenvolvimento sustentável e possibilitam uma maior integração e equilíbrio entre as três dimensões deste desenvolvimento - social, econômica e ambiental - e seus aspectos institucionais e de governança. Os ODS oferecem uma oportunidade para desencadear uma mudança a visão geral do sistema, de modo a construir um futuro sustentável em um mundo cada vez mais 
interconectado. Mesmo contemplando 17 Objetivos, 169 metas e mais de 300 indicadores propostos, os ODS fornecem orientação vaga quanto ao seu alcance, na melhor das hipóteses (COSTANZA, 2016).

Desta forma, faz-se necessário o desenvolvimento de indicadores afinados com os ODS e que incorporem um constituinte do ambiente natural, por meio de uma visão holística e processos mais inclusivos (SCHLEICHER et al, 2018). Diante desta necessidade, foi proposto um novo modelo de avaliação incorporando critérios associados à resiliência ecossistêmica, tendo como pano de fundo a redução da pobreza e como componentes principais sete dimensões ou princípios de sustentabilidade de sistemas socioambientais (SSA), que englobam práticas de governança democrática.

O sistema de indicadores resultante foi denominado "avaliação de prosperabilidade" (FERREIRA et al., 2017) e seu arcabouço teórico-conceitual é expresso no neologismo "prosperabilidade" (que mescla os vocábulos sustentabilidade e prosperidade), vislumbrando a possibilidade de um modelo de desenvolvimento que seja simultaneamente promotor de sustentabilidade forte.

Os ecossistemas costeiros são zonas de alta produtividade primária com geralmente boa acessibilidade e como tal, sempre foram centros preferenciais de ocupação antrópica, sendo vistos como um imenso potencial de exploração. Além de serem focos de biodiversidade e fonte de recursos naturais consideráveis, estes ambientes fornecem uma ampla gama de serviços ambientais (BURKE et al, 2001).

6 Portanto, as zonas costeiras fornecem uma grande variedade de bens e serviços que, aliados a suas belezas naturais, transformam estes ambientes em atratores para a população mundial, tanto para habitação permanente como para turismo, representando para as sociedades humanas um espaço de alto valor, servindo como local de lazer, de turismo ou de moradia de grandes populações urbanas e sendo alvo da exploração desordenada e predatória (BURKE et al, 2001; HALPERN et al., 2008; 2012).

7 Situada na Região Hidrográfica VIII (RH VIII) do estado do Rio de Janeiro Figura 1), a cidade de Macaé é vista como principal polo de instalação de empresas relacionadas às atividades de extração de petróleo e gás, resultando em degradação dos bens e serviços ambientais nesse território (HERCULANO, 2012; SOFFIATI, 2011). A identidade da cidade e sua estrutura social, vocações econômicas e seus recursos coletivos foram modificados juntamente com seu aparelho produtivo e seu grande crescimento. Este crescimento não trouxe uma expansão virtuosa, harmoniosa e bem distribuída, trazendo para o município um desequilíbrio (FAURÉ; HASENCLEVER, 2005). No caso de Macaé e da região Norte-Fluminense, a literatura aponta ainda que decisões assimétricas nas políticas públicas relacionadas à priorização das atividades da economia do petróleo resultaram em desequilíbrio no processo de desenvolvimento territorial (SILVA et al., 2015). A cidade de Rio das Ostras por sua vez, configura-se como a segunda cidade com maior crescimento no Brasil, com 190,39\% entre os anos de 2000 e 2010, de acordo com dados do IBGE, divulgados no ano de 2011, relativos ao Censo 2010 (IBGE, 2010). 
Figura 1: Região Hidrográfica Macaé e das Ostras, RH-VIII

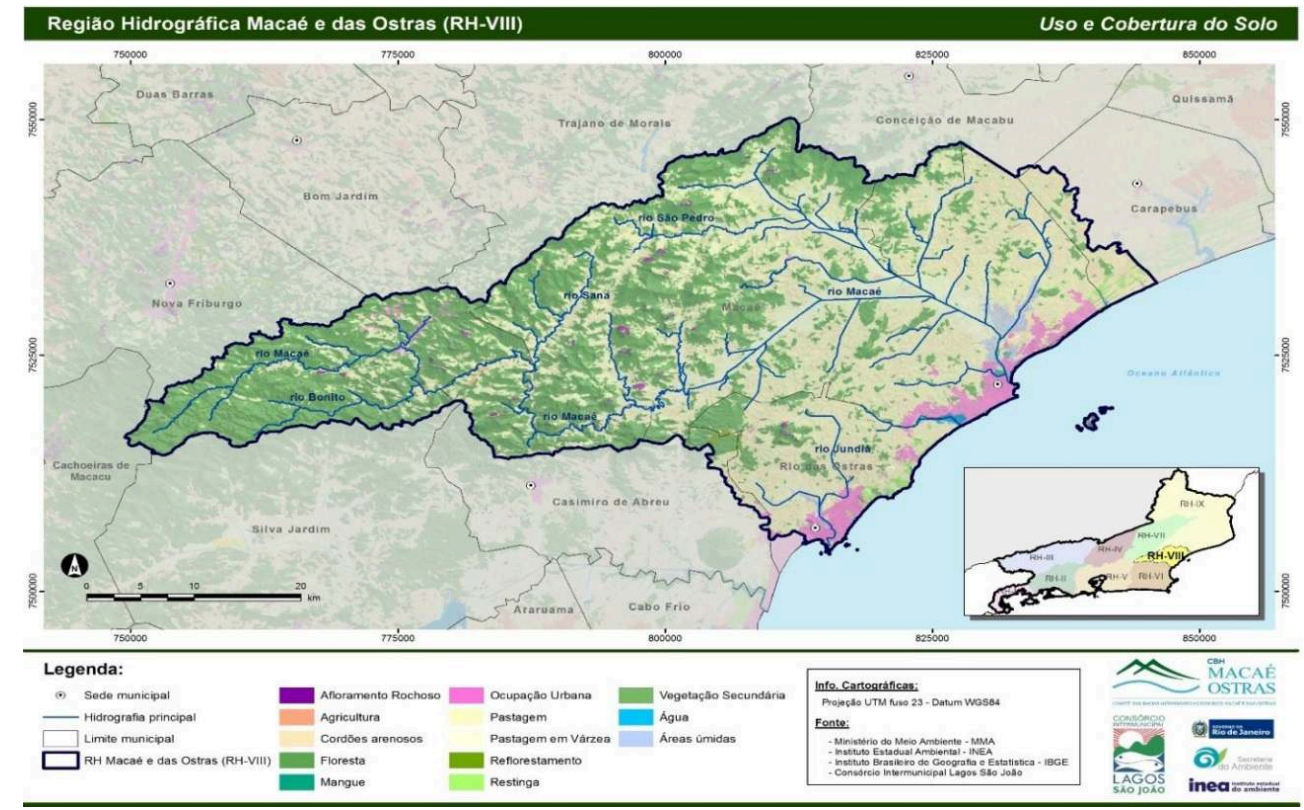

Fonte: Comitê de Bacia Hidrográfica dos Rio Macaé e Das Ostras. Disponível em: http:// cbhmacae.eco.br/site/index.php/mapas/uso-e-cobertura-do-solo/

A concentração populacional em espaços de exclusão caracterizados por pobreza hídrica extrema (GUIMARÃES; FERREIRA, 2018; GUIMARÃES, 2019) é associada a um modelo de desenvolvimento focado na economia do petróleo em detrimento de outras vocações locais (SILVA et al., 2015). Considerando a integridade ecossistêmica marinha, de estuários, lagoas costeiras, áreas úmidas e de recarga de aquíferos, o quadro geral dos distritos urbanos dos municípios de Macaé e Rio das Ostras aponta para a hipótese de que a zona costeira regional apresenta maiores desafios para alcançar as metas estabelecidas pela Agenda 2030 do que a RH-VIII como um todo (GUIMARÃES; FERREIRA, 2018).

Dados a importância ambiental das zonas costeiras, a necessidade de gestão sustentável e conservação dos oceanos e a dependência de questões locais e regionais para o alcance dos ODS, objetiva-se com o presente artigo apresentar os resultados da aplicação da metodologia de avaliação de prosperabilidade na zona costeira da RH-VIII do estado do Rio de Janeiro, comparando os resultados da avaliação com aqueles obtidos para a região hidrográfica.

\section{METODOLOGIA}

\section{Avaliação de prosperabilidade}

10 Partindo-se do pressuposto que é necessário ampliar o conceito de sustentabilidade, aliando uma avaliação sistemática acerca da resiliência ecossistêmica com princípios de sustentabilidade em gestão ambiental, de governança democrática e de redução da pobreza, de forma a vislumbrar um modelo de desenvolvimento alternativo que simultaneamente seja promotor de sustentabilidade, de equidade e de bem-estar para todas as populações humanas do planeta, foi desenvolvida a metodologia de avaliação de prosperabilidade (FERREIRA et al., 2017). Fundamentada no modelo proposto por 
Anderies, Janssen e Ostrom (2004), a metodologia baseia-se no emprego de um sistema de indicadores composto por parâmetros elencados em função dos sete princípios (ou dimensões) da sustentabilidade necessários ao funcionamento adequado dos sistemas socioecológicos (terminologia original de Ostrom, aqui denominada SSA, conforme autores da corrente da economia ecológica): 1 . Integridade do SSA; 2. Eficiência e manutenção dos recursos; 3. Oportunidades de vida e sustento suficientes; 4. Engajamento da sociedade civil e governança democrática; 5. Equidade inter e intrageracional; 6. Interconexão escalas local/nacional/global e 7. Precaução e adaptabilidade. Aplicando o modelo conceitual de SSA e os sete princípios de sustentabilidade descritos pelos autores, pode-se situar o conceito de "prosperabilidade".

11 Para cada um dos sete princípios de sustentabilidade, Ferreira et al. (2017) propuseram um conjunto de quatro subcomponentes e três testes de aderência aos interesses comuns, descritos por Larson, Wiek e Keller (2015), resultando em 49 parâmetros necessários à avaliação. Cada um dos quatro subcomponentes dos princípios de sustentabilidade possui três níves de pontuação, de acordo com critérios específicos: 0 (situação socioambientalmente insustentável), 10 (situação intermediária em termos de gestão sustentável das águas) e 20 (situação promotora de sustentabilidade forte). Para os parâmetros associados aos testes de aderência aos interesses comuns, a pontuação 20 é obtida apenas quando há aderência aos três testes, pontuação 10 para aderência a dois testes e pontuação 0 obtida nos outros casos. A pontuação conferida a cada um dos subcomponentes das múltiplas dimensões da sustentabilidade assim resulta da integração entre os resultados da pesquisa de percepção ambiental e informações de fontes secundárias.

Uma representação esquemática da metodologia é apresentada na figura 2. 
Figura 2: representação esquemática da estrutura metodológica da avaliação de prosperabilidade.
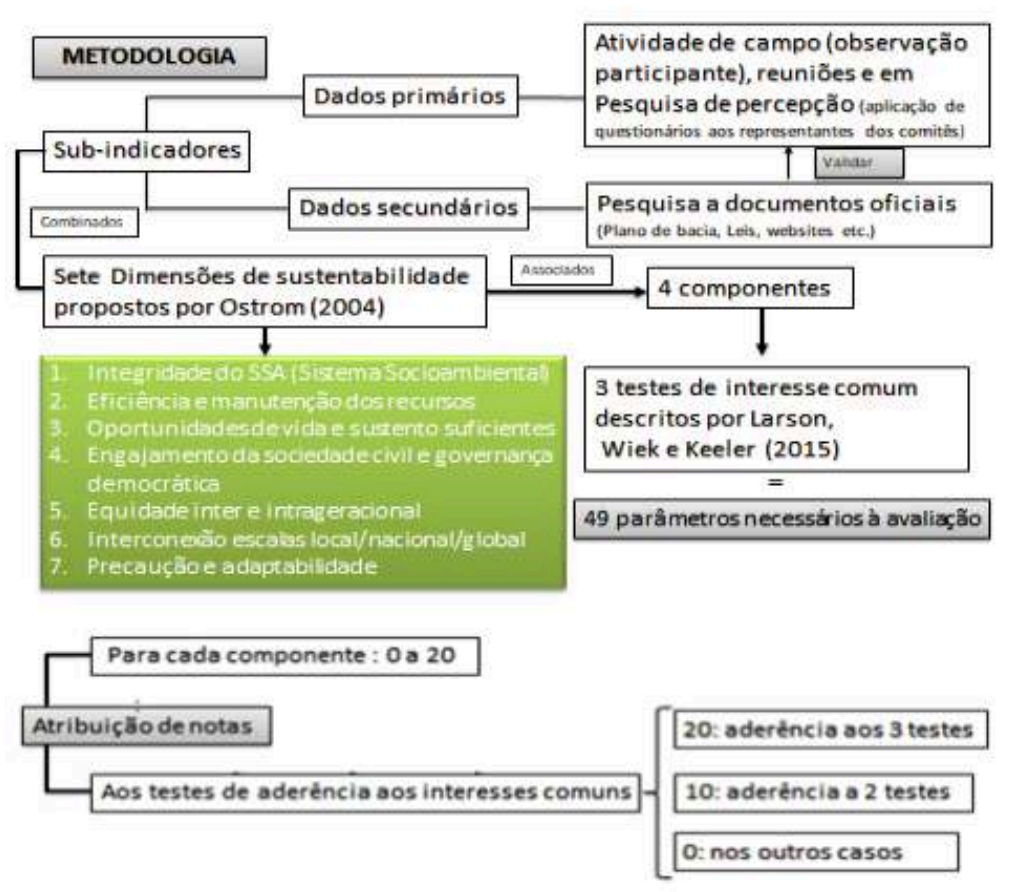

Fonte: MACHADO et al., 2019.

13 Os componentes associados ao princípio "integridade do SSA": 1- Fronteiras oficialmente definidas (10 pontos para SSA com fronteiras definidas por organizações não governamentais ou organismos internacionais não sancionadas pelo Estado); 2 Extensão territorial expressiva das bacias hidrográficas coberta por áreas protegidas (20 pontos para mais do que $50 \%$ da bacia protegida e nenhum ponto para extensâo protegida menos do que 10\%); 3 - Boa qualidade da água nas cabeceiras das bacias hidrográficas, devido à falta de fontes de poluentes e à expressiva área com cobertura florestal conservada (20 pontos para cobertura florestal em área igual ou maior do que $50 \%$ do território da bacia e abundância de espécies indicadoras de boa qualidade de água); e 4 - Baixo nível de ocupação em regiões de mata ciliar, baixa ocorrência de, desmatamento e de desvio irregular de água na bacia hidrográfica (20 pontos para zonas ripárias sem ocupação nem atividades humanas no SSA). Os três (3) testes de interesse comum são: Teste A- Participação da sociedade na elaboração de planos diretores; Teste B- Mecanismos de comando e controle da política ambiental implementados e funcionando adequadamente; Teste C-Dados sobre a qualidade das águas superficiais e subterrâneas disponíveis para o público em geral.

Os componentes associados ao princípio "manutenção e eficiência dos recursos" são: 1Número suficiente de estações hidrométricas públicas e privadas em operação (20 pontos para múltiplos estações em funcionamento e existência de séries históricas de dados disponíveis e acessíveis ao público); 2- Cadastro de outorga e dados de cobrança de usuários de água existentes e disponíveis para consulta do público em geral (20 pontos para sistemas de informação com dados atualizados e completos sobre o uso da água para pequenos e grandes usuários da bacia hidrográfica disponibilizados para a sociedade); 3 - Sistemas de tratamento de esgoto e instalações de saneamento básico 
dos núcleos urbanos implementados e operando com eficiência adequada para: toda a população urbana ( 20 pontos), ou para mais de $50 \%$ da população (10 pontos), ou para menos de $50 \%$ da população (0 ponto), e 4 - Estratégias de enfrentamento de condições de escassez hídrica sazonal elaboradas pelo Poder Público com a participação da população (20 pontos para existência de estratégias participativas desenvolvidas pelo governo em execução). Para este princípio foram definidos os seguintes testes: Testa AGrandes e pequenos usuários autodeclaram seu consumo de água para o Estado; Teste B - Montante expressivo do valor arrecadado com impostos e taxas gastos na manutenção e operação de sistemas de água e esgoto e; Teste C - Instalação e manutenção de instalações de monitoramento públicas e privadas realizadas com celeridade e periodicamente.

O princípio "existência de meios de subsistência e oportunidades suficientes" apresenta componentes de avaliação tais como: 1 - Elevado IDH (20 pontos para IDH maior do que 0,7, sendo desejável o emprego de dados de IDH estimados a nível regional); 2 - Famílias dependentes do extrativismo com bom nível de trabalho e renda (20 pontos para condições nas quais quaisquer indivíduos diretamente dependentes da extração de recursos naturais não processados tem o direito legal de exercer suas atividades extrativistas no território da bacia hidrográfica, prosperando graças a elas); 3 - Baixo percentual da população urbana vivendo em habitações subnormais, sem acesso a saneamento básico ( 20 pontos para $0 \%$ a $5 \%$ da população urbana de baixa renda em condições abaixo da linha de pobreza e nenhum ponto para percentuais inferiores a 20\%); 4 - Pequena ocorrência de êxodo rural devida à falta de oportunidade e de meios de subsistência suficientes nas zonas rurais (20 pontos para existência de abundância de oportunidades econômicas para prosperar na zona rural da bacia hidrográfica ou dados indicativos de alto êxodo rural regional). Para este princípio foram definidos os seguintes testes: Teste A - Orçamento participativo para decidir sobre os investimentos públicos de desenvolvimento; Teste B - Atividades econômicas sustentáveis associadas à renda e oportunidades suficientes para pequenos proprietários rurais e, Teste C Empreendedores privados apoiando inciativas governamentais e/ou da sociedade civil para melhoria de qualidade de vida e enfrentamento das mudanças climáticas.

Para o princípio "engajamento da sociedade civil e governança democrática" apresenta os seguintes componentes: 1 - Arranjos de governança colaborativa induzidos pelas políticas públicas ( 20 pontos em SSA no qual a gestão participativa está oficialmente instituída e regulamentada); 2- Participação social inclusiva na gestão de bacias hidrográficas, mecanismos de cobrança pelo uso da água regulado por lei, com recursos da arrecadação destinados para aplicação por parte dos comitês de bacia (20 pontos para existência de comitês gestores de recursos hídricos com competência deliberativa e normativa e instrumentos específicos de gestão estabelecidos por regulações ambientais implementados); 3 - Envolvimento de todos os setores da sociedade na mediação de conflitos sobre direitos de uso e acesso aos recursos hídricos (20 pontos para comitês de bacia hidrográficas com composição paritária entre Poder Público, usuários e sociedade civil implementados e funcionando adequadamente); e 4 Comunicação eficiente dos comitês de bacia e de outros organismos de gestão ambiental com público em geral (20 pontos para Planos e Programas de Educomunicação acessíveis a toda a sociedade da bacia, de forma a tornar conhecida a atuação e a importância dos Comitês). Os testes correspondes a este princípio são: Teste A - Comitês de Bacia deliberativos e conselhos consultivos de Unidades de Conservação participando ativamente da sua gestão; Teste B - A importância dos comitês de bacia 
para a gestão das águas é reconhecida pela sociedade do SSA, e Teste C - O repasse dos recursos da cobrança pelo uso da água é feito para os comitês de bacia.

O princípio "Equidade inter e intrageracional" estabelece os seguintes componentes: 1 Meio ambiente e os recursos hídricos legalmente considerados como bens comuns (20 pontos quando a legislação em vigor estabelece que a água é de dominialidade pública); 2 - Populações tradicionais com o direito de manter e reproduzir suas práticas culturais em territórios especialmente protegidos definidos por lei (20 quando as populações tradicionais vivem em áreas com acesso à água e com capacidade para preservar suas práticas culturais); 3 - Benefícios derivados dos processos de planejamento ambiental justificando seus custos (eficiência econômica e justiça ambiental): 20 pontos quando os processos de planejamento eficientes e efetivos estão em curso, promovendo condições para que os benefícios dos bens e serviços ecossistêmicos sejam igualmente distribuídos entre os setores sociais; e 4 - Projetos de Educação Ambiental e mecanismos de mediação de conflitos ambientais em funcionamento (20 pontos quando existem programas de educação ambiental formal e informal diversificados, destinados a vários tipos de público, em andamento no SSA). Para esta dimensão de sustentabilidade, os testes são: Teste $\mathrm{A}$ - Existência de mecanismos de estímulo à participação da juventude em comitês de bacia e em conselhos de Unidades de Conservação; Teste B - Ausência de injustiça ambiental no território do SSA e, Teste $\mathrm{C}$ - Interesses públicos norteando a gestão dos recursos hídricos e ambientais, em detrimento dos interesses privados.

Para o princípio "Interconectividade entre as escalas local, nacional e global” foram especificados como componentes de avaliação: 1 - Existência de programas específicos para educação, estímulo à ciência cidadã nas ações de monitoramento ambiental, envolvendo parcerias nacionais e/ou internacionais (20 pontos para existência de programas locais e regionais envolvendo parcerias multiescalares em andamento e 10 pontos para existência de programas em fase de planejamento); 2 - Promoção de ações conservacionistas e práticas agrícolas ambientalmente "amigáveis" (20 pontos para ações de conservação e boas práticas agrícolas implementadas pelos usuários em 75 $100 \%$ do território do SSA e nenhum ponto para menos do que 50\% do território); 3 Não ocorrência de escassez hídrica em áreas densamente povoadas devido à gestão inadequada das bacias hidrográficas do SSA (20 pontos quando se existirem infraestrutura suficiente e planos emergenciais em todo o território da bacia hidrográfica); e 4 - Rede hidrométrica e estações fluviométricas conectadas a sistemas interligados de informações regionais/nacionais de recursos hídricos (20 pontos se existir um sistema de informações de recursos hídricos das bacias hidrográficas do SSA atualizado, disponível para o público e conectado em níveis regional e/ou nacional). Os testes estipulados são: Teste A - Atores locais, nacionais e globais participam ativamente em atividades de gestão das águas e de conservação dos recursos naturais da bacia hidrográfica; Teste B- Trocas comerciais entre pequenos produtores rurais locais e mercados externos contribuem substancialmente para o sustento familiar, e Teste C- Dados dos sistemas de informação sobre recursos naturais a níveis local, regional, nacional e mundial são compatíveis e disponíveis para o público em geral.

19 O princípio "Precaução e adaptabilidade" foi associado aos componentes:1 Planejamento ambiental ocorrendo como um processo contínuo de tomada de decisões, adaptável a um futuro incerto (20 pontos quando as políticas ambientais estão consolidadas, mas são aprimoradas sempre que necessário, 10 pontos quando as políticas ambientais são incipientes e/ou de difícil aprimoramento e nenhum ponto se 
as políticas ambientais forem incipientes e dissociadas dos processos contínuos de planejamento); 2 - Planos de bacias hidrográficas robustos (20 pontos quando o SSA possui plano(s) de bacia(s) hidrográfica(s) detalhado(s), contendo múltiplos cenários de desenvolvimento); 3 -Instrumentos de planejamento urbanos e rural contemplando estratégias para enfrentar a escassez hídrica e as mudanças nas condições ambientais (20 pontos se os documentos do planejamento regional considerarem eventos hidrológicos extremos e mudanças climáticas, e focarem simultaneamente em indicadores ambientais, de forma a garantir o fornecimento de bens e serviços ecossistêmicos e 10 pontos se uma ou outra característica estiver presente no planejamento); 4 - Os limites das Unidades de Conservação (UC) estrategicamente definidos para proteger as bacias hidrográficas (20 pontos para existência de UC oficialmente criadas e 10 pontos para existência de UC propostas, mas não criadas). A esta dimensão de sustentabilidade foram relacionados os seguintes testes: Teste A Planos Diretores municipais atualizados, focando ações sustentáveis e construídos com a participação da sociedade local e com base em atributos ambientais do território do SSA; Teste B - Planos de recursos hídricos, de manejo de Unidades de Conservação e planos diretores urbanos sendo implementados, e Teste C - Capacidade de rever rapidamente os produtos do planejamento territorial em função da alteração das condições socioambientais.

20 Com vistas à obtenção de dados primários de percepção ambiental, foi realizada observação participante das reuniões dos Conselhos de Meio Ambiente das cidades de Macaé e Rio das Ostras e a aplicação de questionários semiestruturados a informanteschave (membros atuantes dos referidos conselhos). Esta etapa do trabalho durou de outubro de 2018 a abril de 2019. Os questionários foram aplicados aos conselheiros municipais de meio ambiente de Rio das Ostras em reuniões oficiais destes conselhos e se estruturam em quatro principais blocos de perguntas onde se pode notar a experiência e o perfil do entrevistado (área de envolvimento, tipo de organização em que atua); sua opinião sobre a gestão da zona costeira da bacia hidrográfica VIII; sua familiaridade com a questão e a percepção dos impactos nesta região; sua opinião sobre o processo de tomada de decisão na gestão dos recursos ambientais e sobre a gestão de UC na Região Hidrográfica em questão. Para elaboração e formatação destes dados e do trabalho como um todo foi utilizado o pacote Libre Office.

\section{Resultados e discussão}

21 O estado do Rio de Janeiro está dividido em nove regiões hidrográficas e dentre estas regiões situa-se a RH VIII, que abrange parcialmente o território dos municípios de Rio das Ostras, Macaé, Nova Friburgo, Casimiro de Abreu, Conceição de Macabu e Carapebus. A Região situa-se entre dois polos de desenvolvimento, ao sul turísticocomercial (Região dos Lagos) e ao norte petrolífero-canavieiro (Campos/Macaé) (SEA, 2014).

22 A porção mais alta da bacia do rio Macaé é caracterizada pela significativa presença de remanescentes florestais, atividades agrícolas e turismo ecológico. Já a parte baixa concentra a maior parcela da população urbana, o setor de serviços e da indústria de transformação relacionada ao apoio das atividades petrolíferas e geração de energia.

As alterações ambientais produzidas na zona costeira dos rios Macaé e das Ostras, agravadas pela reutilização de trechos expressivos de rios, geram impactos como 
erosão, assoreamento, problemas de abastecimento público, cheias e inundações, dentre outros, em todos os ecossistemas da região, inclusive nas áreas urbanas.

Os municípios de Macaé e Rio das Ostras apresentaram um crescimento exponencial, sobretudo acompanhando o crescimento das atividades petrolíferas e turísticas da região. Segundo dados do IBGE, Rio das Ostras configura-se como a segunda cidade com maior crescimento no Brasil, com 190,39\% entre os anos de 2000 e 2010 (IBGE, 2010). Sua população passou de 36.419 pessoas em 2000 para 105.676 pessoas em 2010, enquanto Macaé, ainda segundo o IBGE, apresentou um crescimento populacional de 131.550 em 2000 para 206.728 pessoas em 2010. Tais incrementos trouxeram para a área de estudo uma série de entraves que ameaçam a integridade deste sistema sócio ambiental.

A figura 3 esquematiza os setores sociais e seus atores sociais envolvidos na gestão de recursos ambientais do SSA estudado, juntamente com oito vínculos causais presentes. Neste esquema, os símbolos para as setas de links causais representam: (1) ligações entre recursos e usuários de recursos, (2) ligações entre usuários públicos e provedores de infraestrutura, (3) ligações entre provedores de infraestrutura pública e infraestrutura pública, (4) links entre infraestrutura pública e recursos, 5) entre infraestrutura pública e dinâmica de recursos, (6) ligações entre usuários de recursos e infraestrutura pública, (7) forças externas sobre recursos e infraestrutura, e (8) forças externas sobre atores sociais.

Figura 3: Modelo de SSA presente na zona costeira da RH-VIII

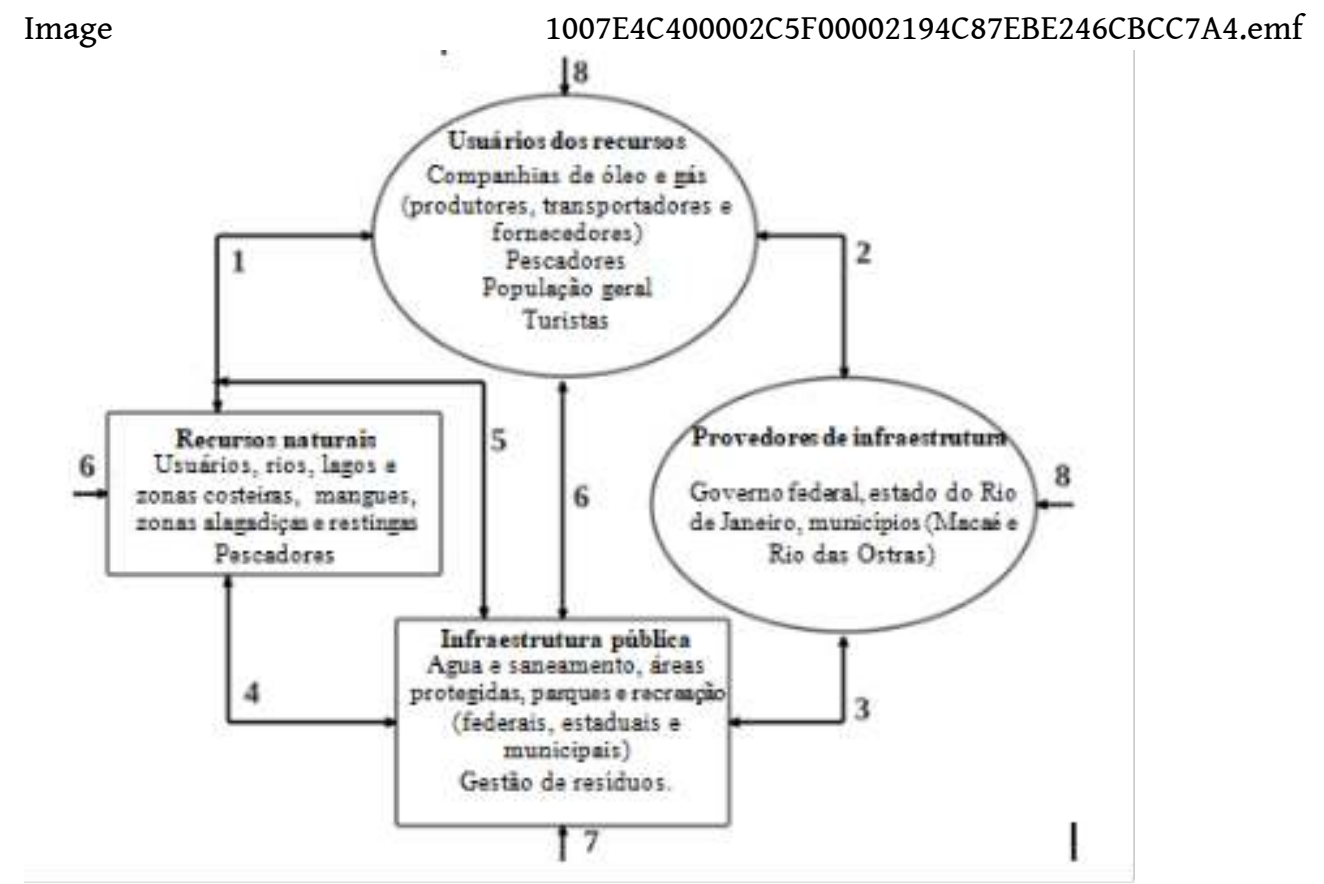

Fonte: Adaptado de Ferreira et al, 2017.

Ao todo, 20 informantes-chave (conselheiros de meio ambiente) responderam ao questionário, sendo nove de instituições governamentais, quatro pesquisadores de universidades, seis de ONGs e sociedade civil organizada. Um conselheiro de meio ambiente optou por não se identificar. 
27 Analisando os resultados obtidos a partir da aplicação dos questionários aos conselheiros de meio ambiente de Macaé e Rio das Ostras, pôde-se notar que há similaridade de opinião em relação aos principais impactos negativos à região em questão, na percepção dos atores entrevistados, em ambos os municípios, no tocante à perda de habitat e/ou biodiversidade (com um leve destaque sobre os demais), à poluição da água e do solo, e às atividades econômicas (com o mesmo percentual de impacto), conforme pode ser visto na figura 4.

Figura 4: Aspectos ambientais e impactos negativos que afetam as bacias hidrográficas da zona costeira da RH-VIII/RJ

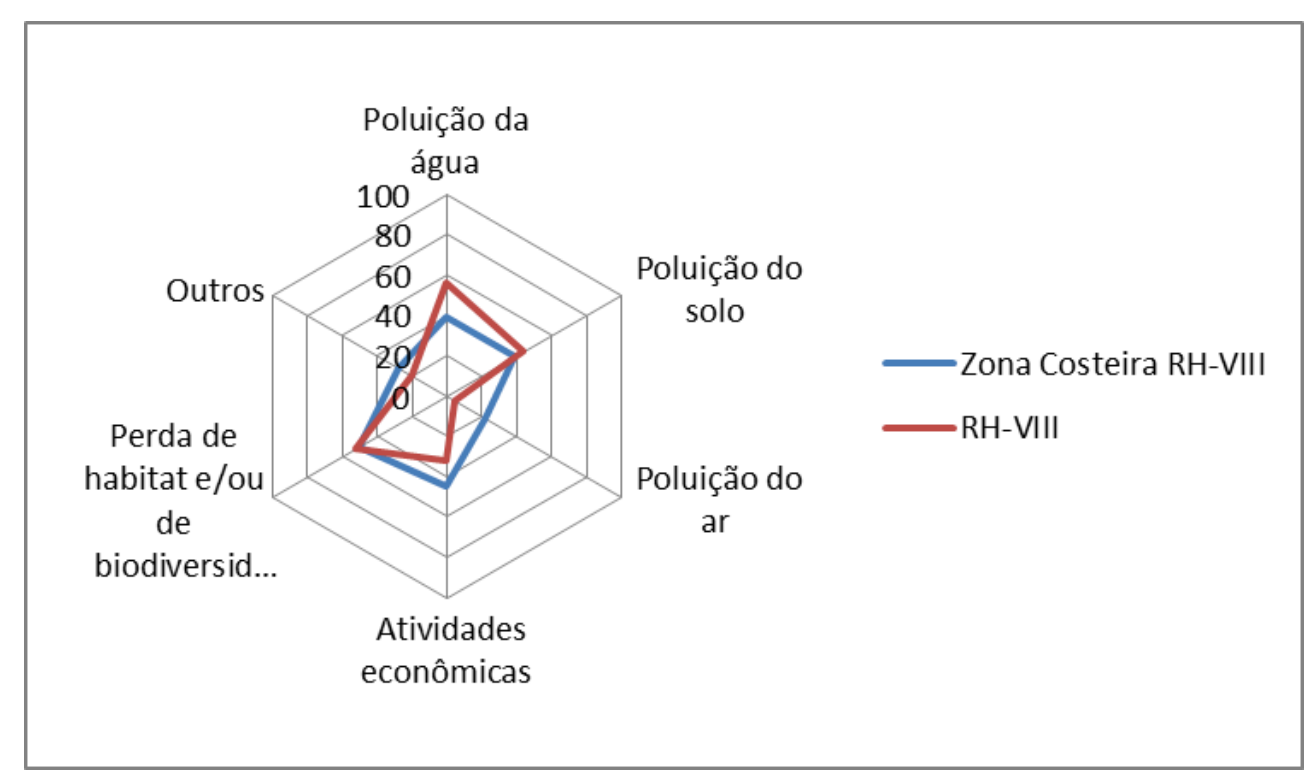

28 As atividades econômicas predominantes e desenvolvidas na região (Fauré e Hasenclever (2005)) configuram-se como principais geradoras de impactos negativos. A poluição de solo e água, também figuram entre os itens mais pontuados. Seguidos da perda de habitats e/ou biodiversidade. Desta forma, estes fatores, ao que tudo indica, demonstram-se estar conectados, uma vez que as atividades econômicas acarretaram em um crescimento populacional desordenado que acarreta e ambos os fatores são geradores de poluição de água e solo e ocasionam perda de habitats e/ou biodiversidade.

29 A exceção do fator poluição da água (que apresentou uma leve redução ao se comparar as duas regiões), os demais fatores são corroborados e ratificados como pontos de destaques negativos tanto para a RH-VIII como um todo quanto para o enfoque com destaque em sua zona costeira.

Na visão dos entrevistados também é possível observar que a poluição doméstica, o uso e ocupação inadequado de terras e a ocupação das margens dos rios constituem os principais impactos negativos sobre as áreas protegidas da zona costeira da região hidrográfica VIII, conforme é possível verificar-se na figura 5 a seguir: 
Figura 5: Impactos negativos sobre as áreas protegidas da zona costeira da região hidrográfica VIII/RJ

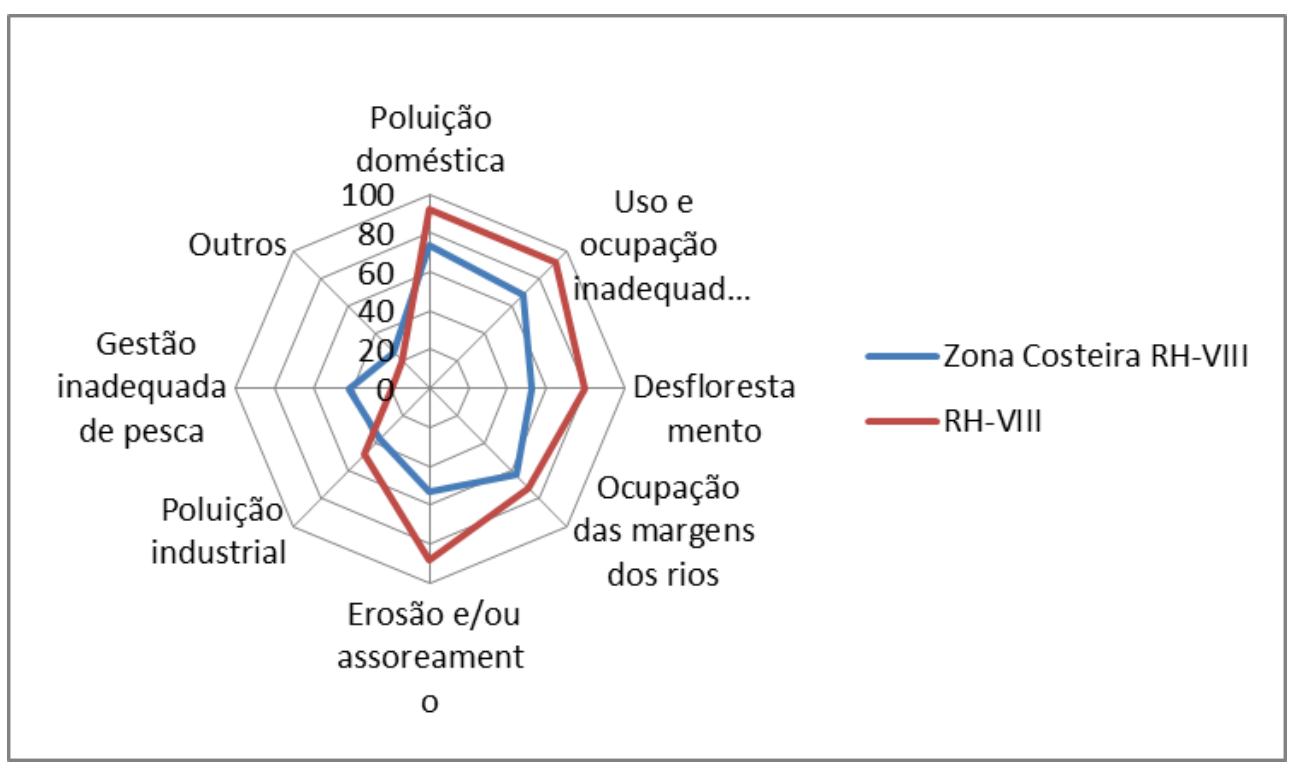

31 O uso e ocupação inadequados de terras e ocupação das margens dos rios podem ser corroborados em virtude da grande concentração populacional em espaços de exclusão, caracterizados por pobreza hídrica extrema citados por Guimarães (2019) e Guimarães e Ferreira (2018). Aliados a percepção dos entrevistados de que a poluição doméstica é um grande promotor de impactos negativos sobre áreas protegidas deste SSA.

A análise das figuras 4 e 5 sugerem que face ao grave problema do esgoto doméstico e dos impactos da pesca, a percepção dos demais impactos negativos pode ter sido obnubilada, uma vez que os dados secundários demonstram o oposto ao se comparar as duas regiões. Outro fator de impacto para estes resultados pode ter sido o quantitativo de informantes-chave, uma vez que para Ferreira et al (2017) predominou-se a visão da sociedade civil enquanto para o enfoque a zona costeira, predominou-se a visão governamental. Portanto, uma possível justificativa para a obnubilação destes resultados pode ser explicada pelos diferentes interesses associados quando ao uso, apropriação e regulação do acesso aos recursos naturais tendo em vista os diferentes perfis de informantes-chave predominantes nos dois enfoques de pesquisa realizados.

Ao compararmos as notas atribuídas aos componentes e testes associados aos sete princípios de sustentabilidade dadas a zona costeira da região hidrográfica VIII com os resultados obtidos por Ferreira et al. (2017) para a região hidrográfica VIII do estado do Rio de Janeiro como um todo, observamos uma redução nos valores atribuídos aos princípios 1 (integridade do sistema socioambiental), 3 (elevado IDH e bom nível de empregos formais) e 6 (interconectividade entre as escalas local/ nacional/global). Para os princípios 4 (engajamento da sociedade civil e governança democrática), 5 (equidade inter e intrageracional) e 7 (precaução e adaptabilidade), os valores atribuídos foram iguais nas 2 avaliações. Já no princípio 2 (manutenção e eficiência dos recursos) os valores obtidos para a zona costeira da RH-VIII foram maiores que os valores obtidos para a RH-VIII como um todo, conforme pode ser observado na pontuação final, apresentada do quadro 1.

A pontuação resultante da pesquisa em dados secundários, juntamente com as categorias de fontes de dados consultadas é apresentada no Quadro 1. 
Quadro 1: Avaliação de prosperabilidade para a RH-VIII e sua zona costeira, validada via pesquisa de percepção ambiental.

\begin{tabular}{|c|c|c|c|c|}
\hline Princípio de sustentabilidade & $\begin{array}{l}\text { Componente/ } \\
\text { Teste }\end{array}$ & $\begin{array}{l}\text { Pontuação } \\
\text { da RH-VIII }\end{array}$ & $\begin{array}{l}\text { Pontuação da } \\
\text { ZC RH-VIII }\end{array}$ & $\begin{array}{l}\text { Tipo de Dado } \\
\text { Secundário usado } \\
\text { na pontuação }\end{array}$ \\
\hline \multirow{7}{*}{$\begin{array}{l}\text { 1. Integridade do sistema } \\
\text { socioambiental }\end{array}$} & 1.1 & 20 & 20 & $1 ; 2$ \\
\hline & 1.2 & 20 & 10 & $1 ; 2 ; 3 ; 4$ \\
\hline & 1.3 & 10 & 10 & $1 ; 3 ; 4$ \\
\hline & 1.4 & 0 & 0 & $3 ; 4$ \\
\hline & Teste A & “+” & “+” & \\
\hline & Teste B & “-” & “-” & 4 \\
\hline & Teste $\mathrm{C}$ & “-” & “-” & $3 ; 4$ \\
\hline \multirow{7}{*}{$\begin{array}{l}\text { 2. Manutenção e eficiência dos } \\
\text { recursos }\end{array}$} & 2.1 & 0 & 20 & $1 ; 4$ \\
\hline & 2.2 & 10 & 10 & $1 ; 2$ \\
\hline & 2.3 & 0 & 0 & $1 ; 2 ; 3 ; 4$ \\
\hline & 2.4 & 10 & 10 & $1 ; 4$ \\
\hline & Teste A & “"” & “"” & $1 ; 2 ; 4$ \\
\hline & Teste B & “-” & “-” & $1 ; 4$ \\
\hline & Teste C & “-” & “-” & 4 \\
\hline \multirow{7}{*}{$\begin{array}{l}\text { 3. Existência de meios de } \\
\text { subsistência e oportunidades } \\
\text { suficientes }\end{array}$} & 3.1 & 20 & 20 & 4 \\
\hline & 3.2 & 0 & 0 & $3 ; 4$ \\
\hline & 3.3 & 10 & 10 & $3 ; 4$ \\
\hline & 3.4 & 10 & 0 & 4 \\
\hline & Teste A & “-” & “-” & 4 \\
\hline & Teste B & “"+” & “.”" & $1 ; 3 ; 4$ \\
\hline & Teste C & “-” & “-”" & 4 \\
\hline \multirow{2}{*}{$\begin{array}{l}\text { 4. Engajamento da sociedade } \\
\text { civil e governança } \\
\text { democrática }\end{array}$} & 4.1 & 20 & 20 & $1 ; 2 ; 3 ; 4$ \\
\hline & 4.2 & 20 & 10 & $1 ; 2 ; 3$ \\
\hline
\end{tabular}




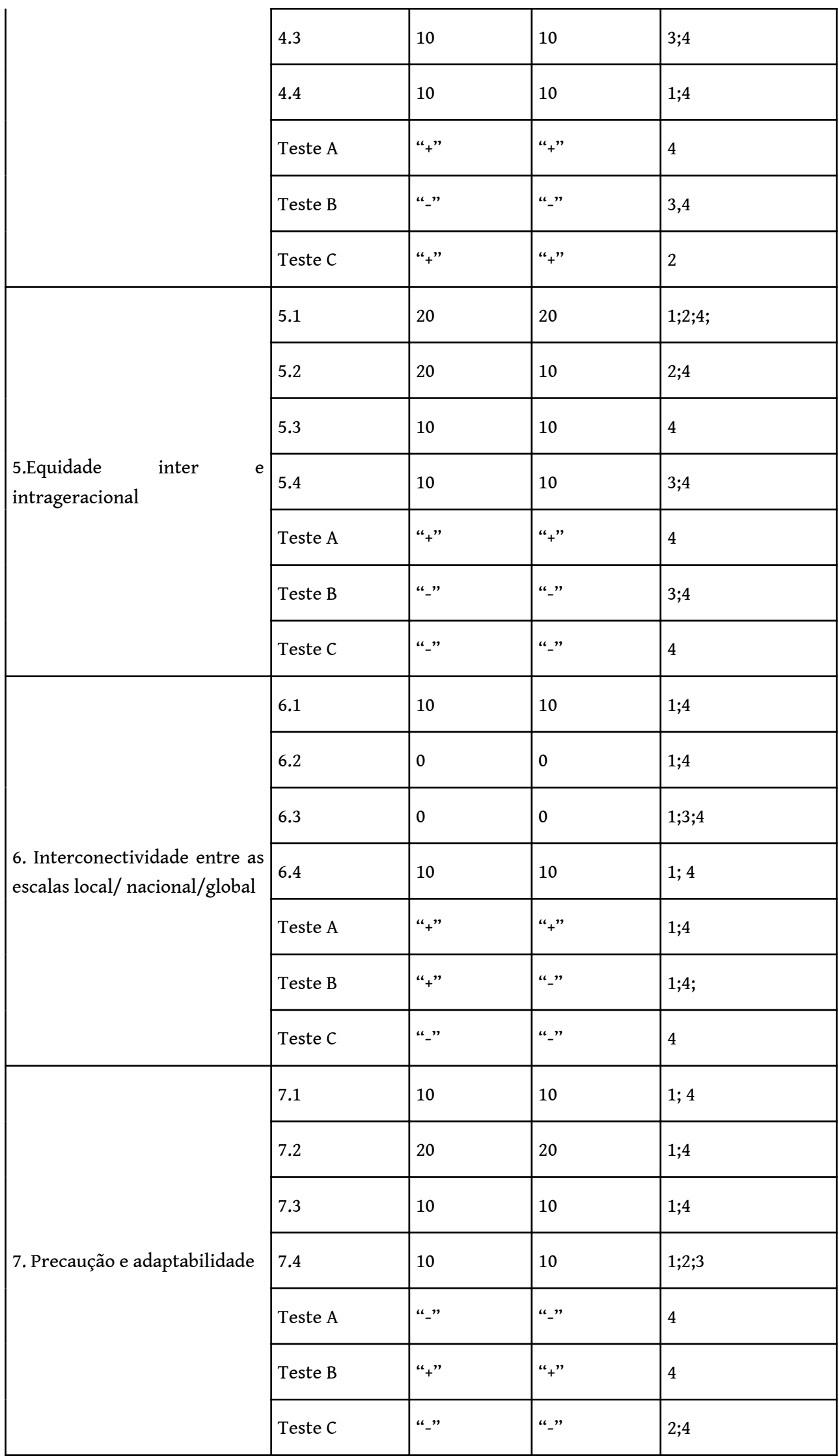


Nota: fontes de dados secundários: 1 = Plano de recursos hídricos da RH-VIII; 2 = legislação

ambiental de níveis federal e estadual; 3 = pesquisa bibliográfica em trabalhos acadêmicos; 4 = outros (relatórios e notícias de internet em websites oficiais, de órgãos ambientais, agências reguladoras e de gestão de recursos hídricos, de empresas e ou de organizações não governamentais).

O valor inferior obtido para o princípio de sustentabilidade número 1 na zona costeira pode ser justificada pela redução na extensão territorial das suas bacias hidrográfica coberta por áreas protegidas quando comparada à região hidrográfica como um todo, queda na qualidade de água nos rios de baixada e nas regiôes estuarinas dos municípios de Casimiro de Abreu, Rio das Ostras e Macaé, assim como expressiva diminuição do percentual do território provido de cobertura florestal conservada quando desconsidera-se a parte alta e média da região hidrográfica e foca-se na porção zona costeira da região. Evidenciada na figura 3, essa percepção dos entrevistados é corroborada pelos dados apresentados no plano de recursos hídricos da região hidrográfica Macaé e das Ostras (SEA, 2014), que possui suas fronteiras definidas por resolução do Conselho Estadual de Recursos Hídricos (CERHI, 2013).

Outro fator que contribui para tal redução de valor é que ao serem desconsiderados diversos rios tributários do rio Macaé presentes na região do alto curso da bacia hidrográfica, ganha maior relevância a proporção dos rios de menor aporte presentes na zona costeira da região hidrográfica e que apresentam grande comprometimento de suas matas ciliares e qualidade de água. Nesse caso encontram-se: o rio Imboacica, onde a predominância de áreas de pastagens e a quase ausência de mata ciliar favorecem a contaminação de suas águas (SEA, 2014), e o Canal Jurumirim (SOFFIATI, 2011).

Cabe destacar que os recursos hídricos, bem como os serviços a eles associados, sustentam os esforços de erradicação da pobreza, de crescimento econômico e da sustentabilidade ambiental. Além disso, o sucesso, a integração e a gestão da água servem de base para a conquista de muitos dos 17 ODS e não só ao ODS 6: assegurar disponibilidade e gestão sustentável de água e saneamento para todos. (GUPPY et al. 2019). Destacando-se assim o papel da água, não só como chave para o desenvolvimento sustentável, em suas três dimensões, ambiental, econômica e social.

Para o princípio 2, ao se restringir o território a uma região mais antropizada e industrializada (zona costeira), há um número maior de estações hidrométricas públicas e privadas em operação do que ao se comparar a região hidrográfica como um todo e ao se comparar os dados divulgados pela empresa gestora do tratamento de esgoto destas áreas e os dados obtidos por meio do Instituto Brasileiro de Geografia e Estatística, há uma melhora deste quadro nos dias atuais, correspondendo o esgoto tratado dos núcleos urbanos a 82,3\% em Macaé e 85,4\% em Rio das Ostras (IBGE, 2010).

Na dimensão 3, que avalia a existência de meios de subsistência e oportunidades suficientes para a população, as cidades de Macaé e Rio das Ostras apresentam elevado IDH e bom nível de empregos formais, sendo 0,764 o IDH de Macaé e 0,773 para Rio das Ostras (IBGE/ PNUD, 2010). Contudo, a existência de aglomerações de elevada densidade populacional em estado de extrema pobreza nas sedes distritais de ambos os municípios, principalmente em Macaé, diferentemente do perfil das populações de menor renda residente nos distritos urbanos da região serrana da RH-VIII explica a queda no valor da total dessa dimensão na zona costeira relativamente à RH como um todo, conforme corroborado pela pesquisa de percepção ambiental aplicada durante este trabalho. 
40 Ainda na dimensão 3, no subcomponente "Famílias dependentes do extrativismo com bom nível de trabalho e renda" há uma redução da nota atribuída, tendo em vista que as populações extrativistas da região costeira constituem-se basicamente de pescadores artesanais locais. Estes pescadores têm na pesca sua única atividade remunerada sendo sua principal fonte de renda para suas famílias (SILVA, 2018) e os impactos antrópicos afetaram negativamente a quantidade de pescado na região (SILVA et al. 2017) e consequentemente a sua qualidade de vida. A questão da desestruturação das atividades da pesca artesanal na região em função dos impactos das atividades econômicas associadas à exploração de petróleo offshore também explicam o menor valor na dimensão 5 na zona costeira quando comparada à RH como um todo.

41 Ao avaliar a interconectividade entre as escalas local/ nacional/global (Princípio 6) o quesito promoção de ações conservacionistas e práticas agrícolas ambientalmente "amigáveis" teve uma nota atribuída para a zona costeira menor que a RH-VIII como um todo uma vez que grande parte da produção rural da região hidrográfica se concentra na parte alta e média, abastecendo mercados consumidores externos ao SSA (SEA, 2014) enquanto a zona costeira apresenta poucos quesitos de promoção de ações conservacionistas, tendo em vista a alta atividade antrópica na região e pouca atividade agrícola.

Para as dimensões 4,5 e 7 há similaridade nos valores atribuídos aos dois territórios em estudo. Atribui-se essa concordância ao fato de grande parte dos quesitos serem mensurados por legislações aplicadas similarmente aos dois recortes. Exemplificando estas similaridades pode-se citar os arranjos de governança colaborativa induzidos pelas políticas públicas, com forte influência dos movimentos sociais, participação social inclusiva na gestão de bacias hidrográficas, mecanismos de cobrança pelo uso da água regulados por lei, com recursos da arrecadação destinados para aplicação por parte dos comitês de bacia, o meio ambiente e os recursos hídricos são legalmente considerados bens comuns e projetos de Educação Ambiental e mecanismos de mediação de conflitos ambientais em funcionamento.

A sistematização das notas atribuídas aos componentes dos sete princípios de sustentabilidade da avaliação de prosperabilidade sob a forma de gráfico permitiu uma comparação entre os dois SSA analisados (figura 6). 
Figura 6: Avaliação comparativa de prosperabilidade para a zona costeira da RH-VIII e RH-VIII como um todo.
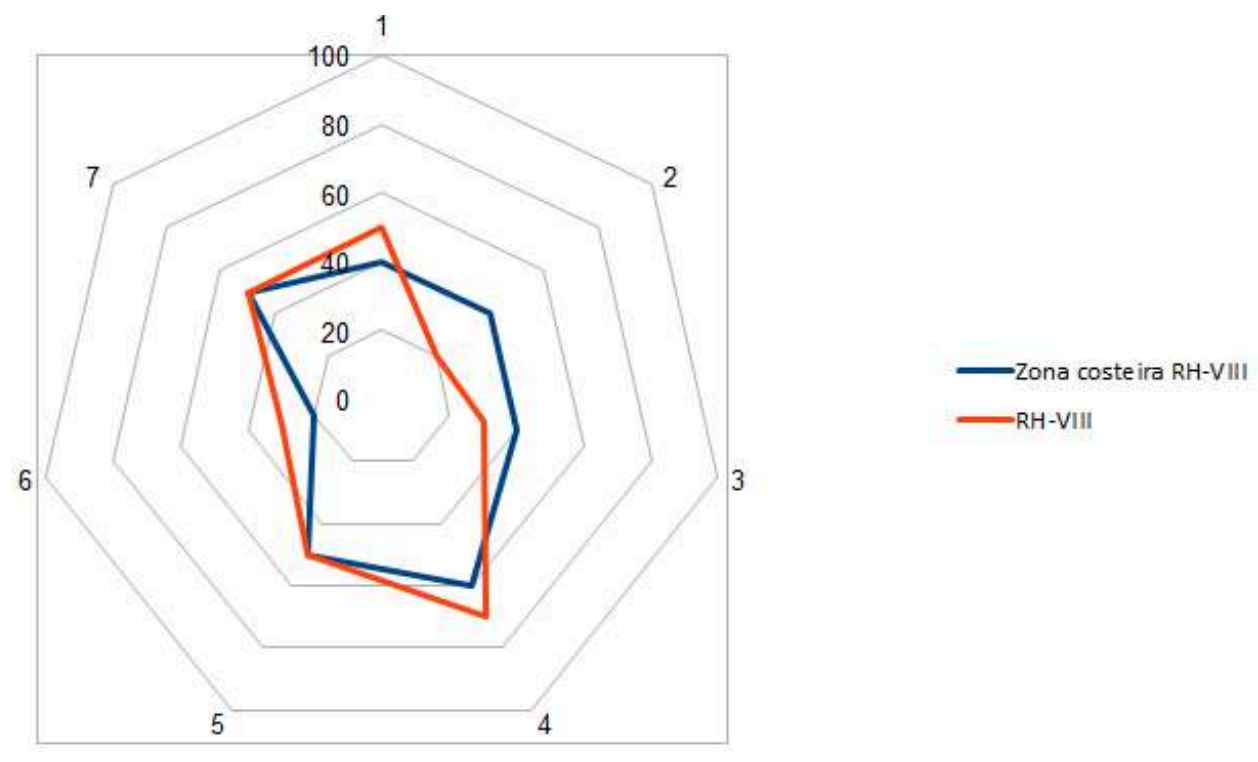

Partindo-se do princípio que para atingir um nível de prosperabilidade ideal seria necessário uma avaliação de $100 \%$ em cada princípio, pode-se notar que os resultados obtidos encontram-se muito aquém do necessário para que seja possível atender a proposta da ONU para os Objetivos de desenvolvimento sustentável até o ano de 2030.

5 Vale ressaltar que para a RH-VIII do estado do Rio de Janeiro, notou-se um comitê de bacia hidrográfica bastante atuante e um plano de recursos hídricos consideravelmente robusto. Estes fatores em consonância com a atuação dos conselhos de meio ambiente e a legislação ambiental refletem em uma boa avaliação do SSA para os quesitos em que estes itens são pertinentes.

Ainda que os dados informados pela concessionária que administra a gestão de esgoto dos municípios de Macaé e Rio das Ostras forneça dados de uma boa cobertura de residências contempladas, há de se destacar que a universalização dos serviços de água e esgoto é diretamente ligada a qualidade de vida da população, além de estar presente no ODS 6 da ONU, água limpa e saneamento devem ser assegurados a toda a população.

47 A partir do intenso fluxo migratório, a formação de comunidades de habitação desprovidas de saneamento básico e infraestrutura amplia-se e com isso ocorre a favelização e a formação de uma enorme periferia urbana, se constatando um elevado processo de segregação do espaço geográfico no município de Macaé. (SILVA;FARIA, 2011), contrariando assim as diretrizes balizadoras dos ODS.

Contudo, considerando novamente que um SSA ideal apresenta uma pontuação igual a 100 em todos os princípios, o fortalecimento dos mecanismos de gestão ambiental democrática e participativa, de forma a garantir os princípios de sustentabilidade forte a qualquer nível, depende do cumprimento destes princípios em escala local, regional, local ou global, possibilitando assim o compromisso firmado em atender os ODS da Agenda 2030.

As sobreposições entre os ODS não podem ser ignoradas e se caso os gestores simplesmente tentem atingir suas metas isoladamente, eles correm o risco de obter resultados perversos, como os descritos por NILSSON et al (2016).

Espaço e Economia, 15 | 2019 


\section{CONCLUSÃO} avaliação de prosperabilidade, que é uma ferramenta de avaliação holística e sistêmica acerca da resiliência de um SSA. A avaliação alia princípios de sustentabilidade, governança democrática e em consonância com as metas desafiadoras presentes nos ODS da agenda 2030 da ONU. A ênfase dada no estudo foi a zona costeira da região hidrográfica número VIII do estado do Rio de Janeiro, de forma a testar na escala reduzida de um SSA local a aplicabilidade da metodologia, desenvolvida inicialmente para o nível regional.

51 Os principais aspectos e impactos ambientais que afetam negativamente as duas regiões hidrográficas são a poluição doméstica, uso e ocupação inadequada do solo, ocupação irregular das margens de rios, desflorestamento e erosão. Já os principais impactos negativos sobre as áreas protegidas da bacia hidrográfica e destacados no enfoque da zona costeira s perda de habitat e ou biodiversidade, poluição da água e poluição do solo.

Porém, há de se ressaltar que alguns fatores podem ter sido obnubilados, tendo em vista que os resultados da avaliação de prosperabilidade obtidos e corroborados com os dados secundários indicam um comprometimento maior da integridade do SSA para a zona costeira ao se compará-la a RH-VIII como um todo. Estes possíveis fatores promotores de obnubilação dos resultados podem estar associados aos diferentes interesses associados quando ao uso, apropriação e regulação do acesso aos recursos naturais tendo em vista os diferentes perfis de informantes-chave predominantes nos dois enfoques de pesquisa realizados.

O estudo focado na zona costeira (região mais antropisada e industrializada) permitiu o levantamento de questões pertinentes aos pontos de degradação ambiental mais influentes na região hidrográfica como um todo. Estes pontos de degradação seguem em consonância com o princípio de sustentabilidade número 6, onde se faz necessário estar cada vez mais interconectado em escalas local/nacional/global para que seja possível promover uma sustentabilidade cada vez maior do SSA. Percorrendo caminhos para se aproximar cada vez mais das audaciosas metas presentes nos ODS.

Considerando que um SSA ideal alcançaria uma média de 100 pontos para a avaliação de prosperabilidade, as médias obtidas para a região hidrográfica VIII (46 pontos na média) e para a zona costeira (41 pontos na média) estão muito aquém dos valores esperados para um SSA equilibrado e em consonância com os ODS. Para ambos os casos, os princípios que mais se destacam negativamente são a falta manutenção e de eficiência no uso dos recursos, a inexistência de meios de subsistência e oportunidades suficientes para os cidadãos e a baixa interconectividade entre as escalas local, nacional e global.

55 Ao confrontar o resultado dos dois casos estudados, percebe-se ainda que a vocação industrial da zona costeira desfavorece as populações extrativistas tradicionais, dada a redução dos incentivos e dos recursos pesqueiros, enquanto a parte media alta da RHVIII apresenta meios de incentivo aos produtores rurais.

56 Desta forma, é preciso ampliar os esforços para melhorar as dimensões de sustentabilidade no SSA, não só em termos regionais, mas principalmente para sua zona 
costeira. Esta área litorânea requer uma atenção maior, dada a sua alta complexidade, de forma a que caminhos em consonância com os objetivos de desenvolvimento sustentável possam ser trilhados, buscando-se promover a sustentabilidade forte, com manutenção da qualidade ambiental, inclusão social, participação democrática e prosperidade econômica para que consigamos atingir a "prosperabilidade".

\section{BIBLIOGRAFIA}

AGÊNCIA NACIONAL DE ÁGUAS - ANA. Diagnóstico da Outorga de Direitos de Uso de Água no País - Diretrizes e Prioridades. Caderno de Recursos Hídricos. Superintendência de Outorga e Cobrança. Brasília: maio de 2005.

BRASIL. Constituição (1988). Constituição da República Federativa do Brasil - Artigo 225. Promulgada em 5 de outubro de 1988.

. 1997. Lei Brasileira da Água - Instituição Política Nacional de Recursos Hídricos. http://www.planalto.gov.br/ccivil_03/Leis/L9433.htm.

2000. Sistema Nacional de Unidades de Conservação. Lei Federal. http:// www.planalto.gov.br/ccivil_03/LEIS/L9985.htm.

2002. Conservação Nacional.

BURKE, Lauretta; KURA, Yumiko; KASSEM, Ken. REVENGA, Carmen; SPALDING, Mark; MCALLISTER, Don. Pilot analysys of global ecosystems: Coastal ecosystems. Washington DC: World Resources Institute, 2001.

CADASTRO NACIONAL DE USUÁRIOS DE RECURSOS HÍDRICOS - CNARH, 2006.

CADERNOS NUPEM; Carta das Águas de Macaé - Contribuição do NUPEM/UFRJ para a Governança dos Recursos Hídricos do Município de Macaé, 2015, p. 13

CONSELHO ESTADUAL DE RECURSOS - CERHI.107. Resolução CERHI-RJ Nº 107/2013. 2013.

COSTANZA, Robert; DALY, Lew; FIORAMONTI, Lorenzo; GIOVANNINI, Enrico; KUBISZEWSKI, Ida, MORTENSEN, Lars Fogh, PICKETT, Kate E., RAGNARSDOTTIR, Kristin Vala; VOGLI, Roberto; WILKINSON, Richard. The Value of the World's Ecosystem Services and Natural Capital (1997).The Globalization and Environment Reader, p. 117, 2016.

FAURÉ, Yves A., HASENCLEVER, Lia. Desenvolvimento local no estado do Rio de Janeiro: Estudo avançado das realidades municipais. Rio de Janeiro, E-Papers, 2005.

FERREIRA, Maria Inês Paes, SHAW, Pamela, SAKAKI, Graham, ALEXANDER, Taylor, UMBELINO, Luis Felipe. Thrivability Appraisals: A Tool for Supporting Decision-making Processes in Integrated Environmental Management." The InternationalJournalofSustainabilityPolicyand Practice13 (3): 19-36, 2017.

GUIMARÃES, Édson. Avelar. Objetivos de Desenvolvimento Sustentável e Pobreza Hídrica: Estudo Comparativo de Comunidades Estuarinas do Município de Macaé/RJ. Macaé, Dissertação de Mestrado em Engenharia Ambiental. Programa de Pós-Graduação em Engenharia Ambiental, Instituto Federal Fluminense, 2019. 
GUIMARÃES, Édson. Avelar; FERREIRA, Maria Inês Paes. POBREZA HÍDRICA EM REGIÕES ESTUARINAS: A Produção De Espaços De Desigualdade Associada À Industria Do Petróleo Em Macaé - RJ.. In: http://www.cneg.org/, 2018, Rio de Janeiro. XIV Congresso Nacional de Excelência em Gestão \& V INOVARSE 2018, 2018. v. único. p. 549-569.

GUPPY, Lisa; MEHTA, Praem; QADIR, Manzoor. Sustainable development goal 6: two gaps in the race for indicators. Sustainability Science (2019) 14:501-513

HALPERN, Benjamin S., Catherine Longo[...];ZELLERET, Dirk. An index to assess the health and beneits of the global ocean. Nature, 488, 615-620, 2012.

HALPERN, Benjamin S.; WALBRIDGE, Shaun; KIMBERLY A. Selkoe [...]; WATSON, Reg. A global map of human impact on marine ecosystems.Science, 319(5865), 948-952. 2008.

HERCULANO, Selene. Revista Nordestina de Ecoturismo, Aquidabã, v.5, n.1, Nov, Dez 2011, Jan, Fev, Mar, Abr, 2012.

INSTITUTO ESTADUAL DO AMBIENTE. Outorga de direito de uso dos recursos hídricos/ Instituto Estadual do Ambiente, - Rio de Janeiro: INEA, 2010. 31p.

INSTITUTO BRASILEIRO DE GEOGRAFIA E ESTATÍSTICA - IBGE. Contagem da população 2010. INSTITUTO DE PESQUISA ECONÔNICA APLICADA - IPEA, ODS - Metas Nacionais dos Objetivos de Desenvolvimento Sustentável: Proposta de Adequação. Disponível em: < http://www.ipea.gov.br/ portal/images/stories/PDFs/livros/livros/

180801_ods_metas_nac_dos_obj_de_desenv_susten_propos_de_adequa.pdf $>$. Acesso em: 06 abril. 2019.

LERNER, Fernanda.; FERREIRA, Inês. Paes. Ferreira, 2016. Avaliação de escassez hídrica em comunidades rurais no entorno de unidades de conservação de proteção integral: índice de pobreza hídrica no assentamento João Batista Soares, Restinga de Jurubatiba, RJ, Brasil. Boletim do Observatório Ambiental Alberto Ribeiro Lamego v. 10, n. 2, 2016.

MACHADO, Rafael. Pereira. Prosperabilidade: uma proposta metodológica holística para avaliação da sustentabilidade de sistemas socioambientais. Dissertação de Mestrado - Instituto Federal de Educação, Ciência e Tecnologia Fluminense. Campos dos Goytacazes, 2018.

MACHADO, Rafael. Pereira, DONNINI, Jade Golzio Barqueta, FERREIRA, Maria. Inês. Paes. Agenda 2030 e gestão sustentável das águas: aplicação da Metodologia "Avaliação de Prosperabilidade" à Bacia Hidrográfica do Rio Una-RJ. 9 REA - Reunião de Estudos Ambientais. Gramado: UFRS, 2019 (no prelo).

. Avaliação integrada da sustentabilidade de sistemas socioambientais: Estudo comparativo de indicadores e índices. $8^{a}$ REA - Reunião de Estudos Ambientais. Porto Alegre: UFRS, 2018.

NILSSON, Måns; GRIGGS, Dave; VISBECK, Martin. (2016) Map the interactions between sustainable development goals. Nature 534:320-322

ORGANIZAÇÃO DAS NAÇÕES UNIDAS. Transformando nosso mundo: a agenda 2030 para o desenvolvimento sustentável. 2015.

- Programa das Nações Unidas para o Desenvolvimento - PNUD. Os Objetivos de Desenvolvimento Sustentável - Dos ODM aos ODS,2015. Disponível em:<http://www.br.undp.org/ content/brazil/pt/home/post- 2015.html> acesso em: 24 abril. 2019.

SCHLEICHER, Judith; SCHAAFSMA, Marije; VIRA, Bhaskar. ScienceDirect Will the Sustainable Development Goals address the links between poverty and the natural environment? Current 
Opinion in Environmental Sustainability, v. 34, p. 43-47, 2018. Elsevier B.V. Disponível em: <https://doi.org/10.1016/j.cosust.2018.09.004>.

SECRETARIA ESTADUAL DO AMBIENTE - SEA. Plano de Recursos Hídricos da Região Hidrográfica Macaé e das Ostras: relatório síntese. Rio de Janeiro, 2014.

. Plano de Recursos Hídricos da Região Hidrográfica Macaé e das Ostras: relatório gerencial Rio de Janeiro, 2014.

SILVA, Jorge Adalberto Aziz; Becker, Beatriz Rohden; Lemes, Rodrigo Martins. Macaé e a sustentabilidade do projeto de "capital nacional do petróleo", 2015.

SILVA, Scheila Ribeiro de Abreu; FARIA, Teresa de Jesus Peixoto. O mapa da migração em macaé: impactos da industrialização no processo de urbanização, 2011.

SILVA, Evelyn Raposo.; FISCHER, Luciano Gomes; MINCARONE, Michael Maia. O saber dos pescadores artesanais de Macaé (RJ): subsídios para conservação e manejo dos recursos pesqueiros marinhos. Boletim do Observatório Ambiental Alberto Ribeiro Lamego, v.11, n. 2, p 59 - 77. Jul./dez., 2017.

SILVA, Evelyn. Raposo. Caracterização da pesca marinha na costa de Macaé (RJ): subsídios para gestão e conservação. 2018. Disponível em: http://ppgciac.macae.ufrj.br/images/

Disserta\%C3\%A7\%C3\%B5es/Evelyn_Raposo_da_Silva.pdf

SISTEMA ONU NO BRASIL - ONUBR. Articulando os Programas de Governo com a Agenda 2030 para o Desenvolvimento Sustentável e os Objetivos de Desenvolvimento Sustentável. 2018.

SOFFIATI, Arthur. Macaé em quatro tempos. In: HERCULANO, Selene. Oficina sobre Impactos ambientais, sociais e urbanos das atividades petrolíferas em Macaé (RJ), Universidade Federal Fluminense, 2011.

\section{RESUMOS}

Os ecossistemas costeiros são zonas de alta complexidade nas esferas ambiental, social e econômica. Desta forma, destaca-se a necessidade de avaliar a sustentabilidade desses sistemas socioambientais de forma integrada, com vistas a subsidiar gestores ambientais nos processos de decisão para traçar rumos que estejam em consonância com os Objetivos de Desenvolvimento Sustentável da Organização das Nações Unidas (ODS-ONU). Objetiva-se com o presente artigo apresentar os resultados da aplicação da metodologia de avaliação de prosperabilidade na zona costeira da RH-VIII do estado do Rio de Janeiro, comparando os resultados da avaliação com aqueles obtidos para a região hidrográfica. 0 sistema de indicadores aqui apresentado permite a identificação dos principais pontos de atenção para a promoção de políticas públicas indutoras de um modelo de desenvolvimento que esteja alinhado com a Agenda 2030 da ONU, buscando aliar o bem-estar social à sustentabilidade para a região.

Les écosystèmes côtiers sont des zones extrêmement complexes dans les domaines environnemental, social et économique. Nous soulignons donc la nécessité d'évaluer la durabilité de ces systèmes socio-environnementaux de manière intégrée, en vue de subventionner les gestionnaires de l'environnement dans les processus de prise de décisions afin de définir des orientations conformes aux objectifs de développement durable des Nations Unies (ONU). L'objectif de cet article est de présenter les résultats de l'application de la méthodologie d'évaluation de la prospérité dans la zone côtière RH-VIII de l'État de Rio de Janeiro, en comparant les résultats de l'évaluation avec ceux obtenus pour la région hydrographique. Le système d'indicateurs présenté ici permet d'identifier les principaux points d'attention pour la 
promotion de politiques publiques qui induisent un modèle de développement aligné sur l'Agenda 2030 des Nations Unies, cherchant à associer protection sociale et durabilité pour la région.

Regarding environmental, social and economic spheres, coastal ecosystems are high complexity areas. Thus, the need to evaluate the sustainability of these socio-environmental systems in an integrated way is important to support environmental managers in the decision-making processes to trace directions that are in line with the United Nations Sustainable Development Goals (UN SDG). The objective of this article is to present the results of the application of the methodology of thrivability appraisal in the coastal zone of RH-VIII of the state of Rio de Janeiro, comparing the results of the evaluation with those obtained for the hydrographic region. The system of indicators presented here allows the identification of the main points of attention for the promotion of public policies aligned to a development model that is adherent to the UN 2030 Agenda, in order ally social well-being to regional sustainability.

Los ecosistemas costeros son zonas de alta complejidad en las esferas ambiental, social y económica. De esta forma, se destaca la necesidad de evaluar la sostenibilidad de estos sistemas socioambientales de forma integrada, con vistas a subsidiar gestores ambientales en los procesos de decisión para trazar rumbos que estén en consonancia con los Objetivos de Desarrollo Sostenible de las Naciones Unidas (ODS) -ONU). Se pretende con el presente artículo presentar los resultados de la aplicación de la metodología de evaluación de prosperabilidad en la zona costera de la RH-VIII del estado de Río de Janeiro, comparando los resultados de la evaluación con aquellos obtenidos para la región hidrográfica. El sistema de indicadores aquí presentado permite la identificación de los principales puntos de atención para la promoción de políticas públicas inductoras de un modelo de desarrollo que esté alineado con la Agenda 2030 de la ONU, buscando aliar el bienestar social a la sustentabilidad para la región.

\section{ÍNDICE}

Palabras claves: indicadores de sostenibilidad. Gestión integrada de recursos costeros. Agenda 2030.

Mots-clés: indicateurs de durabilité, gestion intégrée des zones côtières, Agenda 2030.

Keywords: sustainability indicators integrated coastal zones management, 2030 Agenda.

Palavras-chave: indicadores de sustentabilidade, gestão integrada de zonas costeiras, Agenda 2030.

\section{AUTORES}

\section{ANTONIO VINICIUS LAMBLET MAFORT}

Instituto Federal Fluminense (IFF) - Campus Macaé. Programa de Pós-Graduação em Engenharia Ambiental. Mestrando. E-mail: viniciusmafort@hotmail.com

\section{ANA CAROLINA DA CONCEIÇÃO RODRIGUES}

Instituto Federal Fluminense (IFF) - Campus Guarus. Graduanda em Engenharia Ambiental. Email: carol.portirrera@gmail.com 


\section{MARIA INÊS PAES FERREIRA}

Instituto Federal Fluminense (IFF). Pós-doutora em Gestão Integrada dos Recursos Naturais (VIU/ Bolsista CAPES); Docente do Programa de Pós-Graduação em Engenharia Ambiental (PPEA/ IFFluminense).E-mail: ines_paes@yahoo.com.br

\section{ROMEU E SILVA NETO}

Instituto Federal Fluminense (IFF). Pós-doutor em Ciências Sociais Aplicadas e Docente do Programa de Pós-Graduação em Engenharia Ambiental (PPEA/IFFluminense). E-mail: romeuneto@iff.edu.br 